\title{
CQUniversity
}

\author{
Sandra Arnold
}

\section{Writing about the spiritual side of grieving}

\begin{abstract}
The Collins Dictionary defines 'spirit' as 'the force or principle of life that animates the body of living things'. 'Spiritus' is the Latin word for spirit and also means breath. A bereaved parent in Finkbeiner's study (1998: 238) says, 'If children are part of parents they are not arms or legs, but bones and breath.' Rudolph Steiner (1973) believed that during the first seven years of life, a child shares its mother's spiritual energy in the same way it shared her blood in the womb. I would add to that by saying that in my own experience, and in the experience of many bereaved parents, the spiritual connections with one's child do not end with the death of that child. Although much has been written about the mental, emotional and physical aspects of grieving, discussion of the fourth aspect of the quadrant, the spiritual, is discouraged in western society, where spiritual experiences of the bereaved are accounted for as part of the psychology of grief. This paper examines the spiritual side of grieving and the challenges of writing about it in a creative writing PhD. It draws on research about after-death communication and near-death experiences that aim to determine whether human consciousness survives death. It also reflects on my own writing which argues that the bereaved need not accept the pathologising of their experiences.

Keywords: bereavement; grief; parental bereavement; spirituality.
\end{abstract}

Writing about death was almost non-existent in western societies in the first half of the 20th century. Since then, the proliferation of autobiographical books, magazine and newspaper articles, as well as radio and television programmes, in which well-known personalities describe their experiences of bereavement, have all served to remove the taboos from what is usually considered private. Walter suggests that this writing and public discussion by the bereaved is a rejection of society's 'policing' and 'medicalisation' of grief (Walter 2000: 97). The link between the medicalisation of grief and writings by the bereaved is echoed by Frank (1995: 8), who says, 'The post-modern experience of illness begins when ill people recognise that more is involved in their experiences than the medical story can tell.'

Modern society's embracing of an autobiographical culture in life writing has also contributed to the growing genre of 'death writing' (Grinyer 2006: 207; Walter 2000: 103). However, Grinyer points out that while there might appear to be 'ubiquitous storytelling in the confessional culture of modern Western society apparently obsessed with death' (Grinyer 2006: 220), discussion of death is still unacceptable to many people. This is echoed by English writer CS Lewis, who in 1961 wrote of the way people avoided him after his wife's death, 
or felt awkward about bringing up the subject. Similarly, New Zealand writer Monte Holcroft (1989), in discussing the New Zealand attitude to death after the loss of his own wife, wrote that in a European-based culture, euphemism and platitude were used because the subject was considered unsuitable for conversation. In 2007, Australian journalist Pamela Bone said that when she discovered she had cancer she thought continually about death and the way society avoided its existence (Bone 2007). These observations parallel Riches and Dawson's findings (2000: 143) that, although death is no longer a taboo subject, most people are still uncomfortable with discussion on the topic, especially the death of a child.

Modern western society, with its focus on youth, personal achievement and consumerism, serves to deflect ideas of our own mortality. Death is acceptable in films, books, songs, and in the form of public grieving for the death of famous celebrities, but our own death, and especially that of our children, is too disturbing to contemplate. Life expectancy is western countries has increased and it is assumed the majority of people will live into old age. The media represents a view of the world in which death is associated with the elderly or abnormal circumstances. A child's death preceding that of the parents is therefore considered unnatural as it subverts the expected order.

Davies (2002: 10) describes the human body as a microcosm of society in the sense that it represents everything that has been learned from that society, physically, emotionally and spiritually. The body participates in life as a symbol of its society. The death of an individual is, therefore, the death of the microcosm of the society it represents, and other individuals within the same society are challenged by this death on a biological and social level. In this way, parenthood is deeply challenged by the death of a child. The debilitating pain parents feel after the death of their child is connected to the fact that an integral part of themselves has gone, and to the fact that they now not only know of death, they know death, for 'it has the face of their child' (Klass 1999: $50)$.

Although many academic studies have been conducted on parental grieving there is a paucity of personal-experience stories about grieving the death of a young adult child from cancer. My $\mathrm{PhD}$ thesis addresses this gap with a creative nonfiction memoir titled Sing no sad songs and an exegesis titled Grieving the death of a young adult child from cancer. The creative work is a memoir of my own experience in dealing with the diagnosis, illness and death from cancer of my 23-year-old daughter, Rebecca. The exegesis contextualises Sing no sad songs within the findings of psychological and sociological theories of grief; it analyses the language traditionally used to describe grief and bereavement in western societies; it examines the human affinity with storytelling and the way in which narrative can be used as a tool to help the bereaved assimilate their grief into their changed life story; it also elaborates on these findings with an examination of spiritual perspectives on grief.

After my daughter died I was consumed by the intensity of my loss. As always, when I wanted answers, I turned to books, and the first books on grief I read were by Elizabeth Kübler-Ross. Although my aunt had been a spiritualist I was not interested in exploring that path, probably because of my memories of rather eccentric middle-aged women at the séances I had attended with my aunt when I was a teenager. However, a friend persuaded me to attend a weekend seminar on death and dying. One of the speakers was a doctor and grief counsellor who had trained under Elizabeth Kübler-Ross. The other speaker was described as a channel for a spirit entity, and I intended to dismiss him as a crank until something happened that I could not dismiss. This experience 
appeared in a short story titled 'Autumn Leaves' that I wrote for radio six years later:

Absorbed with the acorn Anna doesn't see my expression as she describes the weeks of chemotherapy, the blonde wig that covered her daughter's bald head, the nausea and vomiting, the weight loss, the pain.

'Then one morning I woke up for no reason. I looked at the clock. It was $2 \mathrm{am}$. I knew something was wrong.' She pauses. 'I looked for her in her room but she wasn't there. I went out into the garden and found her. She was hanging from a tree.' I stop, my breath ripped from my chest.

'When Riccarton House was restored to its former glory I thought it would be the perfect place to celebrate my daughter's 21 st,' she says. 'Instead, we held her funeral here.'

She studies the acorn and the sycamore leaf. 'Before we closed her coffin I took the leaves we'd gathered in England and put them in her hands. A fantail flew into the room, circled around my head, then flew back into the bush. The first time I went to see Kasra he told me about those leaves, and the bird. He couldn't have known. He couldn't possibly have known. But he did.'

Simon - or Shulgi - is walking towards us. Towards me. 'I have to give you a hug,' he says.

I take a step back. I don't want hugs from strangers. Or stories about poems and fantails and Autumn leaves and girls dying in a garden. It hurts to breathe. But he's holding me. And he's saying, 'You didn't need to pack away her music. Play her music again.'

At the seminar, someone gave the name of a channel called Yasmeen who lived in my home town. This meeting with Yasmeen was the catalyst for my healing and reconnection to life. After meeting her I could no longer dismiss the kind of stories told to me by the bereaved, such as how their uncle's favourite book fell off the shelf by itself the day he died; about how their grandmother's rose bush bloomed in the middle of winter; about the scent of violets that permeated the kitchen when no one was there. These anecdotes were often prefaced with something like 'I haven't told this to many people before because ...' The 'because' is related to societal disbelief and the pathologising of experiences outside socially-accepted reality.

Many bereaved parents develop a belief in an afterlife and eventual reunion with their child. This desire for reunion is one of the most common characteristics of the bereaved and is part of the grieving process. However, Worden asserts 'the chronic hope for such a reunion is not normal' (1982: 12) and argues that it is symptomatic of being stuck in denial.

Both faith in a religion and spirituality have as an essential component a belief in something beyond the material. This ranges from the belief in a miracle and search for alternative treatments while the child is still alive to turning back to or developing a new faith in religion after the child has died. Though bereaved parents do not necessarily become involved in a formal religion, many of them consult a medium to connect with their dead child and often experience the presence of their child in other ways. Bowlby (1961) describes such experiences as part of the searching phase of bereavement. 


\section{A definition of spirituality}

'Spirit' originates from the Latin 'spiritus' and means breath. The Collins Dictionary defines it as 'the force or principle of life that animates the body of living things'. Religion and spirituality are often used synonymously. However, for some people spirituality means having a purpose in life and for others it means having an appreciation of nature, of people, and the interconnectedness of all life (Schneider \& Mannell 2006: 4). The patients in Penrod Hermann's study of dying (2001: 68) asserted that their need to be outside in nature was a spiritual need.

Parenting is linked with spirituality in every culture and each has its own rituals for celebrating a new birth. The child is the parents' only link to immortality. When that child dies, the parents have to learn to simultaneously accommodate the bond that transcends death and live in a world that no longer contains the physical presence of the child. The resolution of this paradox is, Klass maintains, not only a psychological process, but also a spiritual journey, which includes the pain of understanding that the child is gone forever. Healing can take place within this pain and transform it, but because the pain and the bond with the dead child are inseparable, the pain will never go away. Several studies show that after surviving the death of their child many bereaved parents feel increased compassion and empathy for others, and formulate new priorities. Some parents also look for something positive in their child's death as a way of helping them find new meaning (Klass 1993a: 344; Riley, LaMontagne, Hepworth \& Murphy 2007: 278). As one parent from Klass' study (1993b: 256) expressed it, 'My pain and loss were not to be the end of life. Rather it was to be a beginning - a beginning to a more compassionate life of quality and caring.' Klass (1999: 86) emphasises that although many parents in the self-help group Bereaved Parents, with which he worked for over 20 years, were able to resolve their grief in a positive way, they all said they would trade the spiritual growth if only they could have their child back.

\section{Hallucinations, visions, dreams and spiritual messages}

Walter (1996: 8) notes that researchers such as Rees (1971) and Parkes (1986) who have studied bereaved people sensing the presence of the deceased, explain this as hallucination. Davies (2001: 1340) refers to the mothers in her study who see their child in the house as experiencing visions. Nonetheless, many bereaved parents report dreams, sightings, sounds and scents associated with their deceased child, as well as appearances of birds, butterflies and animals at significant moments, symbolic messages, finding an object associated with the dead person, and occasionally objects moving by themselves.

The day my family buried my mother-in-law's ashes in our rose garden in Christchurch, a fantail danced on a tree near us and watched the whole proceedings. My elder daughter Susannah said, 'I think it's Momma's way of letting us know she's free.' I told her it was a lovely idea, but the fantail just happened to be there. It was just a bird doing bird things. She explained that in Maori tradition the fantail is considered to be a spiritual messenger. Eighteen months later, when Rebecca died, I stood looking out the window at the rose garden, thinking of that fantail. Immediately one tapped at the glass in front of me. As I moved around inside the house, it appeared outside every window I passed. My head told me this was simply a coincidence, but in my heart, I knew it was not. When the news of Rebecca's death spread and her friends rang, the fantail appeared at the window each time I answered the phone. It 
flew around each of her friends as they got out of their cars and escorted them up to the house. It perched on a tree and watched Rebecca's funeral in our garden and a few days later, it watched my husband loading the equipment the hospital had lent us into his car. The following extract from Sing no sad songs describes one of these incidents:

I extracted myself from their arms and walked to the window overlooking the rose garden where, just eighteen months ago, we'd buried Momma's ashes. I remembered the little fantail that Susannah and Rebecca had seen flitting from branch to branch, watching us. Piwakawaka. The messenger. I drifted into my study and stood wondering what I'd gone in there for. A fantail came right up to the window, tapped on it and looked at me. I called Chris. It flew away. When he stood beside me, it returned to look at him ...

... Bart arrived later in the morning. As he came through the front door he said, 'Hey, the weirdest thing. As I got out of the car a fantail circled round me all the way up to the door.' Then Natasha arrived. I took Bart and her into Rebecca's room. They stood in silence, tears running down their faces, touching Rebecca's hands. Bart told the story of the fantail to Natasha and at the same moment a fantail tapped at the window, looking at Natasha. When John and Sue arrived they said a fantail had come to their window that morning. Susannah said, 'Mum, Rebecca's telling us she's free ...'

... On Monday morning Fabiano rang from Brazil. He'd been driving back home when his mother had phoned to tell him Rebecca had died. He'd driven all the way back to Belo Horizonte where his mother and sister waited up for him till he arrived. I told him about the fantail. At that moment a fantail tapped at my bedroom window.

In Maori culture the fantail is regarded as a spiritual messenger. On many occasions in the years after Rebecca's death, a fantail has appeared in a tree near me, or at the window, during times of overwhelming grief. Somehow, the sight of it always makes me smile. Historian Barry Brailsford says of the fantail's traditional association with death:

It does not cause the passing, is not the agent of change, merely the guardian of the spirit that has decided to move on. Fear is not the companion fantail brings to that moment. Its offering is reassurance, a reminder that we die a thousand deaths in one lifetime; that we let go of the old again and again to give birth to the new. It speaks of beginnings that are without end, of constant renewal, the promise of change and growth. Nothing is lost to us forever. (Brailsford 1999: 113)

Many parents have asked for and received a sign that their child was well and still with them. This parallels Moody's findings that 75 per cent of bereaved parents experience their child's presence within a year of their death (1993: 178). Dyregrov and Dyregrov (2008: 35) explain this perception of the presence of the deceased as the brain 'building bridges' to the dead loved one, and is a way of coping with the loss. These perceptions sometimes take place in a state of altered consciousness and sometimes while fully awake. In many cases, the participants are neither actively seeking nor expecting such encounters and they may happen without the involvement of a psychic. In Sing no sad songs I report Susannah's experience of sensing Rebecca galloping on 
her horse alongside her car on the way to my house where we were all gathering to celebrate my birthday:

'It was like she was racing me. I even turned to look at her, but of course there was no one there. Nevertheless, I was certain she turned and smiled at me. I feel she's really excited, Mum. She's really happy that we're all here together. That we're celebrating this day.'

In a 1990 Gallup poll, 25 per cent of 1,236 American adults reported they 'were in touch with or getting a message from someone who was far away, without using the traditional five senses' (Spencer 2001: 344). Hay and Hunt state that in 1987,18 per cent of a general population sample said they had felt the presence of the dead (2000: para 3.2, table 2).

The following is an extract from Sing no sad songs describing an incident when Rebecca's best friend, Natasha, brought me some roses from her garden, including a rose from a bush called Best Friend, which Natasha had planted in memory of Rebecca:

Natasha told us that on a recent visit to a relative in hospital the 'best friend' necklace that Rebecca had given her had suddenly snapped and fallen to the ground. 'I remembered then that she told me she never wanted to go back to that hospital,' she said. 'So I picked up the chain and took it back to my car and put it in the glove box.'

As we said goodbye to Natasha and Bart six hours later, I pointed to the vase of roses to say thank you once again. The other roses were still tightly furled, but the Best Friend rose had fully opened.

'Weird, eh?' said Bart.

There were many such coincidences in the years following Rebecca's death, including the following incident I describe in Sing no sad songs about my stopping by the art supply shop where Rebecca used to collect her art materials:

I pulled in to the side of the road where I used to wait for Rebecca until she came out laden with coloured card, more brushes, a new craft knife. I thought of her passion for ice hockey and the poster she'd made advertising women's ice hockey: Break some ice. Chill out. Be cool.

Floods of tears.

A bus passed.

On the back was a poster advertising Alpine Ice Rink.

CHILL OUT. BE COOL. SKATE AT ALPINE.

I stared.

A car overtook the bus.

On the number plate, BECKS.

British researchers carried out the first extensive study of visions of the dead in the 19th century. Of the modern researchers who have reported this phenomenon, most position it within the context of a strategy to help the bereaved come to terms with the death (Davies 2001: 1340; Devers \& Robinson 2002: 251; Klass 1993a: 363; Klass 1993b: 255). Haraldsson's 1988 Icelandic study of 127 people found that 100 claimed to have had direct experience of the deceased while fully awake, either through sight, hearing, touch and scent, a sense of presence, or a combination of all of these (Haraldsson 1988-1989: 105). It could be argued that vivid images of the dead 
are part of what Bowlby describes as the 'searching and yearning' phase of grief in which the bereaved are often preoccupied with images of the deceased (Bowlby 1961: 317). Searching can manifest itself in, for example, noticing people who resemble the deceased. This preoccupation with searching accounts for the commonly reported experience of seeing the deceased in the distance, or getting onto a bus. In Sing no sad songs I write about three experiences where I saw someone resembling Rebecca. In only one of these did I think I was really seeing Rebecca, until I realised I was looking at my neighbour. In the other two instances, I was simply struck by the resemblance of the person to my daughter. Nonetheless, preoccupation with searching does not account for experiences that involve other senses. Haraldsson's 1988 study concludes that many cases can be explained as memory distortions, mistaken identity, and hallucinations. However, their findings supported the work of early British researchers in that some visions of the dead happened collectively and that a disproportionate number of experiences occurred at a time when the recipient was unaware of the death or dying of the deceased. They conclude, 'These findings, weak as they are, may permit us to ask if some, or any, of these experiences may possibly be something more than just hallucination' (Haraldsson 1988-1989: 112).

Moody's findings that the dead continue to occupy the mind of the bereaved led him to develop a method of gaining access to this part of the unconscious mind. He drew on accounts of psychomanteums in ancient Greece where people saw apparitions of the dead by gazing into water. He concluded that mirror gazing might have the same effect and constructed a darkened room with a mirror, in which participants, after being led through relaxation techniques, attempted to see the dead loved one in the mirror. Moody's observation of more than 300 participants who were convinced they had had an encounter with the deceased led him to conclude that what had previously been thought to be a paranormal phenomenon could be recreated in a laboratory setting (Moody 1993: xiii), and deserved further investigation.

Dreams about the deceased can symbolise an attitude to the death not consciously understood and can be a way of integrating the loss. Barrett's American study of the dead in dreams examined 1,412 dreams from 149 undergraduates from previous studies as well as 96 students in her own survey. The dreams were classified in four main categories: back-to-life dreams, advice from the dead, leave-taking and the state-of-death. Barrett argues that the first type is consistent with the denial phases of early grief identified by Bowlby, Kübler-Ross and Lindemann, while the leave-taking type reflects what KüblerRoss described as acceptance. Barrett concludes that it may be important for grief counsellors to be aware of dreams such as these as 'this is the dominion of the dead in the lives of the living' (Barrett 1991: 107).

The following passage is an extract from Sing no sad songs that describes a dream I had while camping on a beach in Oman. I interpreted the dream as being the beginning of my acceptance of Rebecca's death:

The air is so hot we leave the tent open all night and sleep in the light of a new moon. I dream of paper lanterns and magic castles and sliding down a snow-covered hill. I dream of kaleidoscopes and crayons. And church bells and fairy tales. And dolls' prams and chocolate coins and oranges. I dream of my friend, Sue, killed in a car crash at twenty. I tell her she still looks young while we've all grown old. I take her hand and feel her soft, cool skin. I say it's terrible that she died so young. She shrugs, and says at the moment of dying the perspective is different, and you realise nothing has changed, and your life 
continues just the same. I argue that I can't see how not having a body is better. She says what you lack in space is made up for by other things ...

... When I wake again, the blackness of night has drained out of the rocks and sand leaving them pale and insipid. I want to tell Chris about my dream, but he is already in the sea. Talin is boiling water on the fire for coffee. The fishermen return to collect their nets. They wave and sail away as sunlight stains the peaks with gold.

Daniel Everett, Chair of the Department of Languages, Literatures and Cultures at Illinois State University, spent 30 years studying a tribe of Indians in the Amazon, the Pirahãs. In a society with dangerous animals and reptiles, without basic hygiene or access to medical help, the Pirahãs' familiarity with and acceptance of death was a feature of their daily lives. Everett describes how their everyday conversations involved references to their dreams, which they believed were as real as their waking lives, and their frequent encounters with spirits. Everett witnessed them channelling spirit entities. On several occasions, all the villagers claimed to see a spirit at the same time and were nonplussed that Everett could not see what was so plain to them. His description of their pragmatism about death appears to refute that what they experienced might be explained as a denial/acceptance phase of early grief (Everett 2008: 131).

Walter (1996: 8) says that societal disbelief and a fear of being thought mad inhibit most people from discussing paranormal experiences and much evidence remains anecdotal. Klass (1999: 92) says that in the early years of the Bereaved Parents group, parents were cautious about mentioning experiences that were outside socially-accepted reality. However, coinciding with an increase of discussion in the media in the 1980s about near-death experiences and communication with the dead, parents have routinely reported paranormal experiences and these are integrated into the group's knowledge about grief. One father summed up the feelings of many parents thus: 'We can't see radio waves; they go right through us. So the idea of the child being here doesn't have to be crazy' (Klass 1999: 92).

Lee suggests the proliferation of publications on parapsychology, New Age philosophies, and near-death experiences have contributed to popular understanding of death as a transition rather than an end. Research into this topic by medical professionals and scientists have authenticated the idea that near-death experiences cannot be dismissed as 'the delirium of resuscitated patients' (2008: 755) and death, far from being a taboo subject, is now increasingly being viewed as 'a key to spiritual evolution' (2008: 757).

Until the 1980s, when new understandings of the bereavement process began to challenge the prevailing theories, detachment from the deceased was considered the desired outcome of normal grieving. New models of grief, which have developed over the last two decades, are based on studies which show normal grieving can encompass holding on to the deceased in memory, in conversation, in memorials and in private rituals. Parents consulting a medium or a channel as part of their continuing bond with their dead child would seem to be a natural part of this process.

The roots of modern spiritualism can be traced to 31 March 1848 when two young sisters, Kate and Margaret Fox, heard raps in their home at Hydesville, New York. They developed a way to communicate with the spirit who identified himself as Charles Rosna (Carroll 1997: 3). Widespread publicity about these events generated a great deal of interest and led, within a few years, 
to the development of spiritualism as a way of life for millions of people in the USA. Its spread in the UK was slower. Some Christians saw it as a return to superstition and ignorance, at best, and as satanic at worst. Others, however, welcomed spiritualism as an affirmation of the existence of life after death and embraced the possibility of spiritual healing (Davies 1999: 44).

Spiritualism increased in influence after World War 1 as the bereaved began to seek mediums in the hope of being able to establish contact with their loved ones who had been killed A further upsurge in the popularity of consulting mediums took place after World War 2. Since then, however, there has been a steady decline (Wallis 2001: 130-31). As the greatest interest in spiritualism was linked with the mass bereavements of two world wars, it would seem logical that a lack of interest in peacetime would follow. In addition, with the growing popularity of spiritualism came an increase in special effects in darkened séances, such as materialisation of physical objects, and the spirits of dead people. The potential for fraudulence and the association of spiritualism with the elderly are further reasons why the movement is unappealing to many in contemporary secular, materialistic, western societies.

Wallis' 2001 study led him to conclude that while bereavement may be the reason some people seek a consultation with a medium, this does not generally lead them into a long-term commitment to spiritualism. Spiritualism, along with death rites in mainstream religions, can be a way of coping with bereavement. The words from the medium are believed to come from the deceased. This brings comfort in that they are seen as evidence that the death of the body is not the end of life, which continues in another form (Davies 2002: 166).

With the emergence of the New Age movement of the 1970s, the channelling of spirit entities by psychics replaced the physical manifestations of spirits prevalent in previous years (Spencer 2001: 350). The entity speaks through the body of the channel, but does not manifest as a separate being. Rather than delivering messages from dead relatives, channelling most often relays philosophical messages and advice about spiritual growth. Spencer argues that the attempt by spiritualists to demonstrate the existence of spirit was undermined by the exposure of many fraudulent mediums and that the decline of physical manifestation of spiritual phenomena coincided with the technical ability to detect frauds. By avoiding these manifestations, he says, channelling is less vulnerable to such exposure, as sceptics can only listen and analyse linguistically the messages of the channelled entity. This parallels Anderson's view (1988: 6) that the popularity of channelling owes more to the endorsement of public figures of the 1970s, such as Shirley MacLaine, and less to the possibility of veridical communication.

The emphasis of channelling on spiritual development and personal growth is also, Spencer notes, more in line with contemporary post-materialist society. Yasmeen, the name of the channel I contacted a month after Rebecca's death, asked me no questions and immediately brought through Raman, the being she channelled. He spoke to me for over an hour, telling me about Rebecca and her dying, my own feelings and actions, and he answered my questions. The impression I had was that I was talking to a wise old man. The words he spoke left a very deep impression on me. The session was taped and I later analysed it for pronunciation, syntax and vocabulary. I repeated this exercise over the following years during which I attended many sessions and courses with Yasmeen, but I could find no comparison between Raman's and Yasmeen's ways of speaking. Although Yasmeen kept her eyes closed while channelling Raman, she knew exactly who was asking a question in a room of up to 40 people. At the end of some of these sessions, Yasmeen walked around the room 
with closed eyes, giving a small gift to each person. Raman's voice addressed each individual by name and gave a personal message of support.

\section{Near-death experiences}

In the 20th century death was medicalised and dying became associated with hospitals and hospices. Life support systems have lengthened and subdivided death into categories like 'biological death', 'brain death' and 'cellular death'. In 1981 Ariès wrote: 'The old signs, such as cessation of heartbeat or respiration, are no longer sufficient. They have been replaced by the measurement of cerebral activity, the electroencephalogram' (1981: 585).

After many years of working with the dying, Kübler-Ross (1991) became interested in the stories of patients who had had near-death experiences. She studied 20,000 cases of clinically dead people from all over the world who had been returned to life, either naturally or artificially, and recorded their experience. This led to her researching the topic and, together with her own laboratory-assisted, out-of-body experience, convinced her that the death of the physical body was simply a transition to the spiritual dimension.

The book that triggered scientific research into this phenomenon was Life after life, by Raymond Moody (1975). As a young philosophy student in 1965, he heard about a psychiatrist, George Ritchie, who, 22 years earlier, had been pronounced clinically dead after suffering pneumonia and had been revived nine minutes later. This was in 1943 when resuscitation techniques were limited to an injection of adrenaline into the heart. Ritchie claimed to have travelled outside his body where he met a Being of Light, experienced a life review and travelled to different realms inhabited by spiritual beings. On his recovery, his experience changed the focus of his life and he later wrote a book, Return from tomorrow, in which he detailed what had happened to him (Ritchie 1978). After meeting Ritchie, Moody began investigating similar stories, for which he coined the term 'near-death-experience' (NDE), and in 1975, by which time he was a psychiatrist himself, he published Life after life. Ritchie's and Moody's books generated enormous public interest and the two men, in a meeting with Kübler-Ross, discussed the importance of further research on the topic. Academic interest was initially cautious, but researchers such as Ring, Sabom and Greyson began publishing the results of their studies and in 1978 founded the International Association for Near-death Studies. Since then there has been increasing medical and psychological research into the topic to learn more about the workings of the mind and brain (Mauro 1992: 54).

Although Moody was the first person to use the expression 'near-death experience', journeys to spiritual realms have been depicted as early as StoneAge art (Kellehear 2007: 23). Similar experiences have been recorded in European, Middle Eastern, African, Indian, East Asian, Pacific and Native American cultures for over 2,000 years (Greyson 2006: 394). The Cheyenne, for example, believed that during a trance state some people could visit the spirit world and return to tell of their experiences (Davies 2002: 152). Such stories are also recorded in the medical literature of the 19th century (Bates \& Stanley 1894: 823-24). A geologist, von St Gallen Heim, who published accounts of those who had survived mountain climbing accidents, neardrownings and war injuries, identified the phenomenon as a syndrome in 1892 (Greyson 2006: 394).

Near-death experiences (NDE) are those reported by people who have been declared dead, as established by electroencephalogram, but who have been 
revived later and claim to have a memory of what happened to them during a time when their brain registered no signs of life (Greyson 2000: 460). A Gallup survey in the USA in 1982 found that four per cent of the population claimed to have experienced an NDE (Parnia 2006: 11). Greyson (2000: 461) estimates that NDEs happen to between nine per cent and 18 per cent of people who have been clinically dead. The increasing number of NDE reports can be explained by the fact that modern cardio-resuscitation techniques are now able to bring many more people back from a state that used to be considered 'death'.

Death-bed visions and similar experiences to the NDE are described by some people in the terminal phase of an illness, though these are referred to in the literature as death-bed visions, or near-death awareness (NDA) (Betty 2006; Wills-Brandon 2001: 196-99). These researchers report that a noteworthy aspect of visions experienced by the slowly dying, or during a NDE, is that the individuals seen are either deceased relatives or strangers, not those who are still living. Kelly (2001: 229-41) points out that although visions of deceased loved ones may be hallucinations produced by expectation, together with an impaired state of mind, healthy individuals also claim to have seen, heard, or sensed a deceased loved one while fully awake. Hospital and hospice workers report seeing 'a wisp of something leave the body at the moment of death' (Wills-Brandon 2001: para 5).

Horacek's 1997 study of 60 cases of NDE and NDA reports nine common descriptions from participants:

1) a feeling of separation from the physical body

2) awareness of being dead

3) moving through a tunnel

4) meeting beings of light and deceased relatives

5) experiencing a feeling of peace

6) reviewing the life just lived

7) having a perception of all time being melded into the 'now'

8) approaching a boundary which may not be crossed

9) being told to return to one's body.

The majority of experiencers report healing effects in the sense that they have no more fear of death, lose interest in the material world and gain more interest in the spiritual (Greyson 2006: 393; Horacek 1997: 149).

Studies have shown that while certain medications can cause hallucinations, those on medication report fewer NDEs than those who are not (Osis \& Haraldsson 1977; Sabom 1982). Van Lommel, van Wees, Meyers and Elfferich (2001: 2044) draw attention to induced near-death experiences after the use of LSD, psilocarpine and mescaline, which produce out-of-body experiences and memories from the past. Similar experiences can also be induced through stimulating various parts of the brain (Mauro 1992: 57). However, induced experiences lack the complete life review and transformational after-effects of a genuine NDE (van Lommel et al 2001: 2044).

Nelson, a neurophysiologist at the University of Kentucky, argues that NDEs can be explained as dream-like states related to what happens during Rapid Eye Movement (REM) sleep, a phase of sleep when vivid dreams often take place (cited Fox 2006: para 2). A form of REM intrusion occurs with a common sleep disorder, known as sleep-paralysis, where the sleeper wakes, but the body is paralysed. The dramatic visual and auditory hallucinations that sometimes accompany sleep-paralysis have been recorded for centuries as supernatural phenomena. The REM centres are located in the brainstem, which remains active for several minutes after other brain areas in the cortex which are 
responsible for vision and hearing register no activity on an EEG. At present there is no conclusive evidence that REM and NDE are related (Fox 2006: paras 26, 27).

Other possible causes of NDE have been attributed to neurotransmitters in the brain (Greyson 2000: 463; van Lommel et al 2001: 2039), lack of oxygen to the brain (Lempert, Bauer \& Schmidt 1994: 372), dissociation - which is the separation of thoughts and feelings from experience (Greyson 2000: 460), and the release of endorphins in response to the stress of dying (Blackmore 1993: 64). However, none of these has been proved as a cause. Crosscultural studies in the USA and India (Osis \& Haraldsson 1977), an African study (Mauro 1992: 57), and studies on children (Morse \& Perry 1990; Sutherland 1995) concluded that the features experienced in NDEs were not influenced by culture, religious beliefs, gender or age. One of the most striking features most experiencers share is that the experience is ineffable (Kelly, Greyson \& Stevenson 1999-2000: 514).

In Sing no sad songs I describe finding Rebecca lying in the hall one night, laughing and talking. She said she felt she had been somewhere and that it was lovely. All time had melded, she said, and she had no idea whether she was talking to us in the past, present or future, or whether she was dreaming or not. I also describe the painting she did for a friend. While I initially took it to be a vortex, he interpreted it as a tunnel and that the profile of the young woman at the entrance to the tunnel signified how close Rebecca was to death. I discuss too, the sensation Susannah had after wondering what dying was like for Rebecca, of leaving her body and looking down on my house where she saw Rebecca's body, before realising that in fact it was her own. With that realisation, she was back in it. She said this experience was a comforting one for her, as she understood that the moment of death was not an unpleasant experience for her sister. Shortly before Rebecca died, she counted the seven people who were present in the room and asked me several times who else had come through the door. Though I told her no one else was there, she insisted there was.

Current medical knowledge cannot explain the causes of NDEs and NDAs and it is acknowledged by researchers that such experiences test the limits of what is known about the relationship of mind and brain and human consciousness (van Lommel et al 2001: 2044). Kelly, Greyson and Stevenson (1999-2000: 514) argue that there is, however, sufficient evidence of the survival of consciousness after death to merit serious attention (Kelly 2001: 229).

In 1997 Dr Sam Parnia, a pulmonary and critical care specialist, set up a oneyear pilot study at Southampton Hospital in England to investigate what surviving cardiac-arrest patients remembered of their experience while clinically dead. The results convinced him to establish a much larger study to try to find out if consciousness and mind were separate from the brain. Consequently, an extensive study of near-death experience - the Awareness during Resuscitation Project - was launched in 2008. Covering a three-year period with 1,500 patients in 25 medical centres in Europe, the USA and Canada, the study aims to examine the brain and consciousness during clinical death. By using hidden images that can only be seen from above the patient, researchers hope to test the validity of out-of-body experiences (The Aware Study 2008). Parnia, who claims he is not religious, says:

should it be discovered that mind or consciousness can exist at the end of life and independently of the brain, this would support the theological and philosophical concept of an afterlife and would suggest that the age-old concept of the 'soul' is the 
same as what scientists now call 'consciousness'. (Parnia 2006:

176)

The results of such research may one day validate the concept of death as a transition rather than an end and the spiritual experiences of the bereaved as more than the imaginings of a grief-deranged brain.

A bereaved parent in Finkbeiner's study said, 'If children are part of parents, they are not arms or legs, but bones and breath' (1998: 238). Rudolph Steiner (1973) believed that during the first seven years of life, a child shares its mother's spiritual energy in the same way it shared her blood in the womb. In my own experience, and in the experience of many bereaved parents, the spiritual connections with one's child do not end with the death of that child.

The most effective way to bring the topic into the mainstream of public discussion is for bereaved people to reject the pathologising of their experiences and to refuse to be embarrassed into silence. As a bereaved mother said in Somanti and August's study (1997: 467), 'How can any of us judge the authenticity of such an experience unless we too have been the parent of a deceased child?'

My decision to write about the spiritual side of grieving in my thesis was made on the basis that while the physical, emotional, and mental aspects of grieving are well covered in academic studies and books by the bereaved, the spiritual, which is the equally valid fourth aspect of the quadrant, is generally ignored or dismissed as part of the psychology of grief. My research began as a way to find logical explanations for my own experiences. My critically and theoretically informed exegesis provided me with a framework to explore and analyse the rational and academic, while my creative nonfiction work allowed me to express, sometimes only through metaphor and imagery, that which was beyond rational, that which was ineffable, that which was pure feeling. To leave out of my writing such an important part of the grief quadrant as its spiritual aspect would be to remain complicit in its marginalisation.

\section{List of works cited}

Anderson R 1988 'Channelling', Parapsychology Review 19.5: 5-9 return to text

Ariès, P 1981 The hour of our death, New York: Alfred A Knopf return to text

Barrett, D 1991 'Through a glass darkly: images of the dead in dreams', Omega: the journal of death and dying 24.2: 97-106 return to text

Bates BC and A Stanley 1984 'What drowning feels like', British medical journal 2: 823-24 return to text

Betty, S 2006 'Are they hallucinations or are they real? The spirituality of deathbed and neardeath visions', Omega: the journal of death and dying 53.1-2: 37-49 return to text

Blackmore, S 1993 Dying to live: science and near-death experiences, London: HarperCollins return to text

Bone, P 2007 Bad hair days, Carlton: Melbourne University Publishing return to text

Bowlby, J 1961 'Process of mourning', International journal of psychoanalysis 42: 317-40

return to text

Brailsford, B 1999 Wisdom of the four winds, Christchurch: Stoneprint Press return to text 
Carroll, BE 1997 Spiritualism in antebellum America, Bloomington, IN: Indiana University Press return to text

Davies, AM 2001 'Death of adolescents: Parental grief and coping strategies', British journal of nursing 10.20: 1332-42 return to text

Davies, DJ 2002 Death, ritual and belief(2nd ed), London: Continuum return to text

Davies, O 1999 Witchcraft, magic and culture, Manchester: Manchester University Press return to text

Devers, E \& Robinson KM 2002 'The making of a grounded theory: after death communication', Death studies 26.3: 241-53 return to text

Dyregrov, K \& A Dyregrov 2008 Effective grief and bereavement support, London and Philadelphia: Jessica Kingsley Publishers return to text

Everett, DL 2008 Don't sleep, there are snakes, London: Profile Books return to text

Finkbeiner, A 1998 After the death of a child, Maryland: Johns Hopkins University Press return to text

Fox, D 2006 'Light at the end of the tunnel', New Scientist 192: 2573 return to text

Frank, AW 1995 The wounded storyteller, Chicago: University of Chicago Press return to text

Greyson, B 2000 'Dissociation in people who have near-death experiences: out of their bodies or out of their minds?', The Lancet 355.9202: 460-63 return to text

Greyson, B 2006 'Near-death experiences and spirituality', Zygon 41.2, June: 393-414 return to text

Grinyer, A 2006 'Telling the story of illness and death', Auto/biography 14.3: 206-22 return to text

Haraldsson, E 1988-1989 'Survey of claimed encounters with the dead', Omega: the journal of death and dying 19.2: 103-13 return to text

Hay, D \& K Hunt 2000, 'Understanding the spirituality of people who don't go to church: a report on the findings of the adults' spirituality project at the University of Nottingham', http://www.facingthechallenge.org/nottingham.php August (accessed 24 September 2010) return to text

Holcroft, MH 1989 The grieving time, Dunedin, New Zealand: John McIndoe return to text

Horacek, J 1997 'Amazing grace: the healing effects of near-death experiences on those dying and grieving', Journal of near-death studies 16.2: 149-59 return to text

Kellehear, A 2007 A social history of dying, Melbourne, Vic: Cambridge University Press return to text

Kelly, EW 2001 'Near-death experiences with reports of meeting deceased people', Death studies 25: 229-49 return to text

Kelly, EW, B Greyson and I Stevenson 1999-2000 'Can experiences near death provide evidence of life after death?' Omega: the journal of death and dying 40.4: 513-19 return to text

Klass, D 1993a 'Solace and immortality: bereaved parents' continuing bonds with their children', Death studies 17: 342-68 return to text

Klass, D 1993b 'The inner representation of the dead child and the world views of bereaved parents', Omega: the journal of death and dying 26: 255-73 return to text

Klass, D 1999 The spiritual lives of bereaved parents, Philadelphia: Taylor \& Francis return to text 
Kübler-Ross, E 1991 On life after death, Berkeley, CA: Celestial Arts return to text

Lee, RLM 2008 'Modernity, mortality and re-enchantment: the death taboo revisited', Sociology 42.4: 745-59 return to text

Lempert, T, M Bauer and D Schmidt 1994 'Syncope and near-death experience', The Lancet 344.8925: 829-30 return to text

Lewis, CS 1961 A grief observed, New York: The Seabury Press return to text

Mauro, J 1992 'Bright lights, big mystery’, Psychology today, 1 July: 54-82 return to text

Moody, R 1975 Life after life, Atlanta, GA: Mockingbird Books return to text

Moody, R 1993 Reunions, New York: Villard Books return to text

Morse, ML and P Perry 1990 Closer to the light. Learning from children's near-death experiences, New York: Villard Books return to text

Osis, K and E Haraldsson 1977 At the hour of our death, New York: Aveon return to text

Parkes, CM 1986 Bereavement: studies of grief in adult life (2nd ed), London: Tavistock return to text

Parnia, S 2006 What happens when we die, Carlsbad, CA: Hay House return to text

Penrod Hermann, C 2001 'Spiritual needs of dying patients: a qualitative study', Oncology nursing forum 28.1: $67-72$ return to text

Rees, WD 1971 'The hallucinations of widowhood', British medical journal, October: 37-41 return to text

Riches, G and P Dawson 2000 An intimate loneliness: supporting bereaved parents and siblings, Buckingham, UK: Open University Press return to text

Riley, LP, LL LaMontagne, JT Hepworth and BA Murphy 2007 'Parental grief responses and personal growth following the death of a child', Death studies 31.4: 277-99 return to text

Ritchie, G 1978 Return from tomorrow, Grand Rapids, MI: Fleming H Revell return to text

Sabom, MB 1982 Recollections of death: a medical investigation, New York: Harper \& Row return to text

Schneider, M and RC Mannell 2006 'Beacon in the storm: an exploration of the spirituality and faith of parents whose children have cancer', Issues in comprehensive pediatric Nursing 29:324 return to text

Somanti, M and J August 1997 'Parental bereavement: spiritual connections with dead children', American journal of orthopsychiatry 67.3: 460-69 return to text

Spencer, W 2001 'To absent friends: classical spiritualist mediumship and New Age channelling compared and contrasted', Journal of contemporary religion 16.3: 2001 return to text

Steiner, R 1973 Karmic relationships, East Sussex, UK: Rudolph Steiner Press return to text

Sutherland, C 1995 Children of the light, New York: Bantam return to text

Van Lommel, P, R van Wees, V Meyers and I Elfferich 2001 'Near-death experience in survivors of cardiac arrest: a prospective study in the Netherlands', The Lancet 358.9298: 2039-45 return to text

Walliss, J 2001 'Continuing bonds: relationship between the living and the dead within contemporary spiritualism', Mortality: promoting the interdisciplinary study of death and dying 


\section{2: $127-45$}

Walter, T 1996 'A new model of grief: bereavement and biography', Mortality: promoting the interdisciplinary study of death and dying 1.1: 7-25 return to text

Walter, T 2000 'Grief narratives: the role of medicine in the policing of grief', Anthropology \& medicine 7.1: 97-114 return to text

Wills-Brandon, C 2001 'Understanding departing visions or deathbed visitation', The journal of religion and psychical research 24: 196-200 return to text

Worden, JW 1982 Grief counselling and grief therapy, New York: Springer Publishing return to text

Sandra Arnold lives in New Zealand and holds a PhD and MLitt in creative writing (CQUniversity). She is the author of two novels and her short fiction has been published and anthologised in New Zealand and internationally and broadcast on Radio New Zealand National. This paper is an expanded version of one she presented at the AAWP 'Margins and Mainstream' conference in Hamilton, New Zealand, November 2009.

\section{TEXT}

Vol 14 No 2 October 2010

http://www.textjournal.com.au

Editors: Nigel Krauth \& Jen Webb

Text@griffith.edu.au 